\title{
The -553 T/A polymorphism in the promoter region of the FGF2 gene is associated with increased breast cancer risk in Polish women
}

Jan Rykala ${ }^{1}$, Karolina Przybylowska², Ireneusz Majsterek ${ }^{2}$, Grazyna Pasz-Walczak ${ }^{3}$, Andrzej Sygut ${ }^{4}$, Adam Dziki ${ }^{4}$, Piotr Kuna ${ }^{5}$

1Department of Plastic, Reconstructive and Aesthetic Surgery, Barlicki Hospital, Medical University of Lodz, Poland

2Department of Chemistry and Clinical Biochemistry, Medical University of Lodz, Poland ${ }^{3}$ Department of Pathology, Medical University of Lodz, Poland

${ }^{4}$ Department of General and Colorectal Surgery, Medical University of Lodz, Poland ${ }^{5}$ Departments of Internal Medicine, Asthma and Allergy, Medical University of Lodz, Poland

Submitted: 31 May 2013

Accepted: 15 June 2013

Arch Med Sci 2015; 11, 3: 619-627

DOI: 10.5114/aoms.2013.35996

Copyright $\odot 2015$ Termedia \& Banach

\section{Abstract}

Introduction: Fibroblast growth factor-2 (FGF2) is an important signalling molecule contributing to angiogenesis, tumour growth and progression and its expression is implicated in breast cancer (BC) development. We investigated whether -553 T/A FGF2 gene polymorphism is associated with the risk and progression of $B C$ in Polish women.

Material and methods: The -553 T/A polymorphism was genotyped in 230 breast cancer patients and 245 control subjects, using a polymerase chain reactionrestriction fragment length polymorphism (PCR-RFLP) approach. Moreover, FastQuant human angiogenesis array was used to measure FGF2 levels in tumour $(n=127)$ and serum $(n=76)$ samples.

Results: The T/A genotypes (OR $=2.12,95 \% \mathrm{Cl}: 1.20-3.74)(p=0.08)$ and the combined heterozygotes T/A and homozygote $A / A(O R=2.18,95 \% \mathrm{Cl}: 1.24-3.83)$ $(p=0.006)$ had an increased risk of BC. The median FGF2 levels in the tumours of A allele carriers were significantly increased compared to T/T patients, whereas in serum FGF2 levels were hardly altered among different genotype carriers. Significantly higher frequency of A allele was found in patients with lymph node metastases $(\mathrm{OR}=2.53 ; 95 \% \mathrm{Cl}: 1.23-5.17)(p=0.009)$ and human epidermal growth factor receptor 2 positive tumour $(\mathrm{OR}=3.22,95 \% \mathrm{Cl}: 1.49-6.99)(p=0.002)$. Furthermore, Kaplan-Meier survival analysis showed that the A allele predicted worse disease-free survival (DFS) in BC patients.

Conclusions: Our study shows for the first time that the -553 T/A FGF2 gene polymorphism may be associated with a risk of $B C$ developing and progression in Polish women and may have prognostic value for the assessment of BC high-risk groups.

Key words: basic fibroblast growth factor, cancer progression, prognostic factor.

\section{Introduction}

Fibroblast growth factor-2 (FGF2 or basic FGF) is a signalling molecule involved in several physiologic processes, and the deregulation of this molecule has been associated with cancer development [1]. Fibroblast growth factor-2 binds to the extracellular domain of FGF receptors, initiating a signal transduction cascade that promotes cell proliferation, motility, and angio-

\author{
Corresponding author: \\ Jan Rykala MD, PhD \\ Department of Plastic, \\ Reconstructive \\ and Aesthetic Surgery \\ Barlicki Hospital \\ Medical University of Lodz \\ 22 Kopcinskiego St \\ 90-153 Lodz, Poland \\ Phone: +48426776741 \\ Fax: +48 426776749 \\ E-mail: \\ janekrykalarykala@gmail.com
}


genesis, which have been linked to key steps in cancer progression [2, 3]. Higher FGF2 levels have been found in the serum and urine of patients with different tumours than in healthy individuals [4-7], and in the serum of patients with metastatic disease than in those with localized disease $[8,9]$. In patients with breast cancer $(\mathrm{BC})$ the potential of FGF2 for diagnostic purposes [10-12] or for monitoring the clinical course of disease $[13,14]$ has been investigated. Some studies in BC indicated that FGF2 has been associated with a more angiogenic phenotype and poor prognosis $[10,15,16]$. In contrast, some papers have reported that elevated serum FGF2 in BC cases is associated with good prognosis $[13,17]$. Another study reported that FGF2 expression is associated with the absence of lymph node metastasis, longer recurrence-free survival and overall survival [17-19]. Presented results are conflicting; therefore the prognostic value of FGF2 in primary breast carcinoma remains contentious. Most significant discrepancies were related to the studies of FGF2 serum levels, suggesting that this test is not useful as a diagnostic and prognostic factor in BC. Additionally, physiological elevation of FGF2 during normal menstruation can also influence the precise interpretation of the pathological elevation of FGF2 in pre-menopausal BC patients [20]. On the other hand, the FGF2 levels determined in nipple fluid of $B C$ patients proved to be a high sensitivity and specificity test for the detection of $B C$ as well as a predictive factor. However, this test is invasive and therefore less useful in BC screening programmes. For this reason, functional polymorphisms in the promoter region of the FGF2 gene, which are associated with high levels of FGF2, may turn out to be a more useful prognostic factor for BC than serum or nipple fluid levels. Especially that many associations between common single nucleotide polymorphisms (SNPs) and breast cancer risk and outcomes have been previously reported [21-24]. Three single nucleotide polymorphisms of the FGF2 gene promoter have been described: a -553T/A, -834 T/A, -921 C/G [19]. The prevalence of the TA genotype was reported in proliferative diabetic retinopathy patients [25]. Additionally, the levels of FGF2 expression in serum among the patients carrying the TA genotype were elevated significantly in comparison with TT homozygotes, whereas the $-834 \mathrm{~T} / \mathrm{A},-921 \mathrm{C} / \mathrm{G}$ polymorphisms failed to affect serum FGF2 level [26].

The aim of our work was to investigate the influence of $-553 \mathrm{~T} / \mathrm{A}$ polymorphisms in the promoter region of the FGF2 gene on the occurrence and progression of $\mathrm{BC}$ in the Polish population.

\section{Material and methods}

\section{Patients}

This study included 230 Caucasian non-familial BC female patients, recruited at the Department of
Surgical Oncology, Nicolaus Copernicus Hospital in Lodz, Poland, between 2005 and 2010, without previous history of neoplastic disease and blood transfusions. None of the BC patients received neoadjuvant therapy. The subjects were 36 to 84 years old with median age of 60.5 years. All patients had histologically confirmed primary BC (ductal breast carcinoma $(n=192)$ and lobular carcinoma $(n=38))$. Additionally, serum samples were collected preoperatively from BC patients $(n=76)$ and tumour tissue samples were obtained during primary curative resection $(n=127)$. Women were considered postmenopausal if they had self-reported their last menstrual bleeding being at least 12 months before the reference date or had undergone a bilateral oophorectomy. A database comprising detailed clinical data regarding diagnosis and histopathological variables of invasive BC patients was created (Table I). Clinical outcomes including overall survival (OS) and disease-free survival (DFS) were available for 102 patients. The median OS was 64.5 months and the median DFS was 59.5 (range: 7-99 months). The control population $(n=245)$, matched for age (median age 58.1 (from 35 to 78 years)), with no previous or concurrent malignant disease, was recruited at the same hospital. Written informed consent was obtained from all participating subjects and the study was approved by the local Ethics Committee of the Medical University of Lodz.

\section{Blood sampling}

Blood samples of all patients and controls were collected into $10 \mathrm{ml}$ ethylenediaminetetraacetic acid (EDTA) tubes and stored at $-70^{\circ} \mathrm{C}$ until use. Genomic DNA was obtained from $250 \mu$ l of whole blood using a commercially available kit according to the manufacturer's instructions (QIAamp DNA extraction kit; Qiagen, Hilden, Germany). Each DNA sample was stored at $-20^{\circ} \mathrm{C}$ until analysis.

Additionally, BC patients' sera were obtained by peripheral venous blood collection that was carried out on the day of surgery. Blood samples were collected without anticoagulant into serum separator vacutainers and allowed to coagulate for $20 \mathrm{~min}$ to $30 \mathrm{~min}$ at room temperature. Sera were separated by centrifugation (1200x g, $10 \mathrm{~min}$ ), and all specimens were aliquoted immediately, frozen, and stored in $\mathrm{a}-70^{\circ} \mathrm{C}$ freezer.

\section{Breast tissue sampling}

Breast cancer specimens of at least $100 \mathrm{mg}$ were obtained from the tumour core at the time of surgery from each patient. The specimens were verified by the study pathologist to be invasive mammary carcinomas or benign breast disease. Fragments of benign lesion tumour and representative specimens with more than $70 \%$ tumour cells 
from $B C$ were then immediately shock frozen and cryopreserved $\left(-70^{\circ} \mathrm{C}\right)$ for subsequent assay preparations. For FastQuant human angiogenesis array analysis, tissues of all specimens were homogenized in the extraction buffer $(0.005 \mathrm{M}$ Tris- $\mathrm{HCl}, \mathrm{pH}$ 8) with addition of a cocktail of protease inhibitors (Roche Applied Science, Meylan, France) in the presence of $0.5 \%$ Triton X-100. Homogenates were centrifuged for $10 \mathrm{~min}$ at $13500 \mathrm{x}$ g. The protein concentration of supernatants was calculated by the Qubit ${ }^{\mathrm{TM}}$ Quantitation Fluorometer (Invitrogen, California, USA).

\section{Genotyping}

Genotypes of the -553 T/A polymorphism in the FGF2 promoter were determined by PCR-based $B s e N I$ restriction fragment length polymorphism [27]. The following primers were used: $5^{\prime}$ - CTTTCTGCGTCGTCTAATTCCAG-3' (forward primer) and 5'-CCAAAAGACGAGGGGTACAA-3' (reverse primer). $B s e N I$ digestion would cleave PCR products deriving from the A allele but not those deriving from the $T$ allele. The polymerase chain reaction (PCR) was carried out in a MultiGene TC9600-G thermal cycler (Labnet International, Inc. Edison, NJ, U.S.A.), in a total volume of $25 \mu \mathrm{l}$, containing $50 \mathrm{ng}$ genomic DNA, 10 pmol each primer (Eurogentec, Seraing, Belgium), $200 \mathrm{mM}$ each dATP, dCTP, dGTP and dTTP (Qiagen, Hilden, Germany), $20 \mathrm{mM}$ Tris- $\mathrm{HCl}$ (pH 8.4), $50 \mathrm{mM} \mathrm{KCl}, 1.5 \mu \mathrm{l}$ of $\mathrm{MgCl}_{2}$, and 1 unit of Taq polymerase (Qiagen, Hilden, Germany). The thermal cycling conditions were initial denaturation $5 \mathrm{~min}$ at $95^{\circ} \mathrm{C}$, followed by 35 cycles of $30 \mathrm{~s}$ at $95^{\circ} \mathrm{C}, 30 \mathrm{~s}$ at $60^{\circ} \mathrm{C}$ and $30 \mathrm{~s}$ at $72^{\circ} \mathrm{C}$. Polymerase chain reactionamplified DNA was digested with $2 \mathrm{U} B s e N I$ (Fermentas, Vilnius,. Lithuania) in a total volume of $18 \mu \mathrm{l}$. The solution was incubated at $37^{\circ} \mathrm{C}$ for $16 \mathrm{~h}$. Fifteen $\mu \mathrm{l}$ aliquots of the digest were electrophoresed on an $8 \%$ horizontal polyacrylamide gel (PAGE) and visualized by ethidium bromide staining.

\section{Evaluation of oestrogen receptors, progesterone receptors and human epidermal growth factor receptor 2}

Levels of oestrogen receptors (ER), progesterone receptors (PR) and human epidermal growth factor receptor 2 (HER2) within the tumours of the cases had been determined by immunohistochemistry as part of the routine clinical practice. For immunohistochemical staining, 4- $\mu$ m-thick sections cut from formalin-fixed, paraffin-embedded tissue were used. After deparaffinization in xylene and hydration in graded ethanol solutions, the sections of breast carcinoma tissue ER and PR staining were subjected to pre-treatment in a microwave oven in citrate buffer, in order to enhance antigen retrieval. The EnVision+ System-HRP (DAB) (DakoCytomation) was used for the detection of immunostain-
Table I. Clinical characteristics of patients with invasive breast cancer

\begin{tabular}{|c|c|}
\hline Clinical characteristics & $\begin{array}{l}\text { Patients }(n=230) \\
\text { number/frequency }\end{array}$ \\
\hline \multicolumn{2}{|l|}{ Age at diagnosis: } \\
\hline$>49$ & $189 / 0.82$ \\
\hline$\leq 49$ & $41 / 0.18$ \\
\hline \multicolumn{2}{|l|}{ Menopausal status: } \\
\hline Post-menopausal & $159 / 0.65$ \\
\hline Pre-menopausal & $81 / 0.35$ \\
\hline \multicolumn{2}{|l|}{ Histological grade: } \\
\hline G1 (Well differentiated) & $20 / 0.08$ \\
\hline G2 (Moderately differentiated) & $84 / 0.37$ \\
\hline G3 (Poorly differentiated) & $105 / 0.46$ \\
\hline Unknown & 21/0.09 \\
\hline \multicolumn{2}{|l|}{ Nodal status: } \\
\hline$N(-)$ & $126 / 0.55$ \\
\hline $\mathrm{N}(+)$ & $104 / 0.45$ \\
\hline \multicolumn{2}{|l|}{ Tumour size: } \\
\hline $\mathrm{T} 1$ & $86 / 0.37$ \\
\hline $\mathrm{T} 2$ & $119 / 0.52$ \\
\hline $\mathrm{T} 3 / \mathrm{T} 4$ & 25/0.11 \\
\hline \multicolumn{2}{|l|}{ Oestrogen receptors: } \\
\hline Positive & $158 / 0.69$ \\
\hline Negative & $71 / 0.31$ \\
\hline Unknown & $1 / 0.00$ \\
\hline \multicolumn{2}{|l|}{ Progesterone receptors: } \\
\hline Positive & $109 / 0.48$ \\
\hline Negative & $120 / 0.52$ \\
\hline Unknown & $1 / 0.00$ \\
\hline \multicolumn{2}{|l|}{ HER2: } \\
\hline Positive & $179 / 0.78$ \\
\hline Negative & $42 / 0.18$ \\
\hline Unknown & $9 / 0.04$ \\
\hline
\end{tabular}

ings performed with primary antibodies against ER and PR (Dako, Glostrup, Denmark). The immunostainings were performed according to the protocol described by the manufacturer. The dilutions of primary antibodies against ER and against PR were $1: 50$. All incubations with the primary antibodies were conducted at $20-25^{\circ} \mathrm{C}$ for ER and PR lasted $60 \mathrm{~min}$. As a final step, counterstaining with haematoxylin was performed. Positive controls (antigenpositive tissue) for the immunostaining technique were used. Tumours were categorized as ER or PR positive if nuclear staining was observed in at least $10 \%$ of nuclei. The immunostaining for HER2 was performed using HercepTest ${ }^{\circledR}$ (Dako, Glostrup, Den- 
mark) strictly according to the protocol described by the manufacturer. Human epidermal growth factor receptor 2 was scored negative when no staining was observed or membrane staining was observed in less than $10 \%$ of the carcinoma cells. All immunostainings were performed in the Department of Pathology, Chair of Oncology, Medical University of Lodz.

\section{FASTQuant ${ }^{\circledR}$ microspot assays for FGF2 quantification}

A FASTQuant human angiogenesis array for angiogenesis factor quantification was run according to the manufacturer's instructions (Whatman Schleicher and Schuell, Dassel, Germany). Each kit contains glass slides arranged with 16 nitrocellulose pads on which reference markers and capture antibody for analyses in that array are dotted in triplicate using nanodot technology. The kit also includes biotinylated detection antibodies and recombinant antigen standards for generating a standard curve. The slides were imaged using a GenePix scanner (Axon, Molecular Devices, Wokingham, Berks, UK). In order to evaluate the microarray images, we customized the spot intensities comparison routines available within "The R Project For Statistical Computing" version 2.5.1 (R Foundation for Statistical Computing, http:// www.r-project.org). A log transformation of the signal from the samples permitted comparison to the standard curve to approximate the concentrations of the angiogenic molecules. The dynamic range for FGF2 was $12.2-12,500 \mathrm{pg} / \mathrm{ml}$.

\section{Statistical analysis}

The allelic frequencies were estimated by gene counting and genotypes were scored. The $\chi^{2}$ test was used to compare discrete variables, genotypic distributions and Hardy-Weinberg equilibrium. The odds ratios (ORs) and 95\% confidence intervals (Cls) were calculated by using a logistic regression model. T-test (for normal distribution) or Mann-Whitney test (for non-normal distribution) was used to compare each parameter between two groups. An ANOVA test was used to identify parameters that would make significant differences between more than two groups; Scheffe's test was then used to test the significance of difference in each identified parameter between any two groups. Overall survival and DFS were calculated using the Kaplan-Meier method and compared with a log-rank test at $p<0.05$ level of statistical significance. Statistical analyses were performed with Statistica 8.0 PL (StatSoft Inc.).

\section{Results}

This study comprised 230 BC patients and 245 healthy controls. The FGF2 genotype distributions in $\mathrm{BC}$ patients and control groups were compatible with Hardy-Weinberg expectations (BC patients $\chi^{2}=0.37$, control group $\chi^{2}=0.49$ ). Associations between FGF2 polymorphisms and BC risk are shown in Table II. Major allele T homozygotes serve as the reference group, and heterozygotes and minor allele A homozygotes are separately and together compared. The FGF2 T/A genotype $(\mathrm{OR}=2.12$, 95\% Cl: 1.20-3.74) and the combined T/A plus A/A genotypes $(\mathrm{OR}=2.18,95 \% \mathrm{Cl}: 1.24-3.83)$ had an increased risk of $B C$ and this was statistically significant $(p=0.026)$.

We assessed whether the -553 T/A polymorphism was associated with various clinical parameters such as histological grade, tumour size, lymph node, ER, PR and HER2 status (Table III). We found higher risk of metastasis development in lymph node for combined T/A-A/A genotypes ( $O R=2.53$; $95 \% \mathrm{Cl}: 1.23-5.17)$. Additionally, the A allele genotype was significantly associated with HER2 positive tumour ( $\mathrm{OR}=2.53,95 \% \mathrm{Cl}: 1.24-5.17)$. No significant correlation was noted between A allele genotype and age at diagnosis, tumour grade, size, and hormonal receptors status (ER and PR). However, the frequency of the FGF2 A allele was marginally higher in ductal than lobular carcinomas. The levels of FGF2 were analysed in 127 tumour sample and 76 serum samples of the subpopulation of BC patients (Table IV). Significantly higher FGF2 tumour levels were demonstrated in BC patients with the TA genotype of the -553 T/A polymorphism compared with those with the TT wild type genotype. No statistically significant difference

Table II. The -553 T/A promoter polymorphism of FGF2 gene in subjects with breast cancer (BC) and control group

\begin{tabular}{|lcccc|}
\hline Genotype & $\begin{array}{c}\text { BC patients }(n=230) \\
\text { Number (frequency) }\end{array}$ & $\begin{array}{c}\text { Control group } \\
\text { Number (frequency) }\end{array}$ & OR $(95 \% \mathrm{Cl})^{*}$ & Value of $p$ \\
\hline T/T & $191(0.83)$ & $224(0.91)$ & Ref. & Ref. \\
\hline T/A & $38(0.17)$ & $21(0.08)$ & $2.12(1.20 ; 3.74)$ & 0.008 \\
\hline A/A & $1(0.00)$ & $0(0.00)$ & NA & NA \\
\hline T/A-A/A & $39(0.17)$ & $21(0.08)$ & $2.18(1.24 ; 3.83)$ & 0.006 \\
\hline
\end{tabular}

*Statistical significance and odds ratio for the dominant model (TA and AA vs. TT); $a\left(\chi^{2}=0.37, p=0.84\right), b\left(\chi^{2}=0.49, p=0.59\right)$ as compared with Hardy-Weinberg distribution. Statistically significant results $(p<0.05)$ indicated in bold. 
Table III. The -553 T/A polymorphism of the FGF2 gene in relation to clinical, pathological and biological characteristics in breast cancer patients

\begin{tabular}{|c|c|c|c|}
\hline Clinical characteristics & T/A-A/A vs. TT & OR $(95 \% \mathrm{Cl})$ & Value of $p$ \\
\hline \multicolumn{4}{|l|}{ Age at diagnosis: } \\
\hline$>49$ & $32 / 157$ & & \\
\hline$\leq 49$ & $7 / 34$ & $1.01(0.41-2.48)$ & 0.841 \\
\hline \multicolumn{4}{|l|}{ Menopausal status: } \\
\hline Post-menopausal & $32 / 127$ & & \\
\hline Pre-menopausal & $17 / 64$ & $1.05(0.59-2.04)$ & 0.887 \\
\hline \multicolumn{4}{|l|}{ Histological type: } \\
\hline Lobular carcinoma & $3 / 35$ & & \\
\hline Ductal carcinoma & $36 / 156$ & $2.69(0.78-9.24)$ & 0.104 \\
\hline \multicolumn{4}{|l|}{ Tumour grade: } \\
\hline G1 and G2 & $17 / 87$ & & \\
\hline G3 & $20 / 85$ & $1.20(0.59-2.45)$ & 0.602 \\
\hline \multicolumn{4}{|l|}{ Tumour size: } \\
\hline$<2 \mathrm{~cm}$ & $14 / 72$ & & \\
\hline$>2 \mathrm{~cm}$ & $25 / 119$ & $1.08(0.53-2.12)$ & 0.841 \\
\hline \multicolumn{4}{|l|}{ Nodal involvement: } \\
\hline $\mathrm{N}$ negative & $14 / 112$ & & \\
\hline $\mathrm{N}$ positive & $25 / 79$ & $2.53(1.24-5.17)$ & 0.009 \\
\hline \multicolumn{4}{|l|}{ ER: } \\
\hline Positive & $25 / 133$ & & \\
\hline Negative & $14 / 57$ & $1.31(0.63-2.70)$ & 0.466 \\
\hline \multicolumn{4}{|l|}{ PR: } \\
\hline Positive & $15 / 94$ & & \\
\hline Negative & $24 / 96$ & $1.57(0.77-3.17)$ & 0.210 \\
\hline \multicolumn{4}{|l|}{ HER2: } \\
\hline Negative & $24 / 155$ & & \\
\hline Positive & $14 / 28$ & $3.22(1.49-6.99)$ & 0.002 \\
\hline \multicolumn{4}{|l|}{ MVD: } \\
\hline Low $(\leq 26)$ & $7 / 23$ & & \\
\hline High $(>26)$ & $4 / 19$ & $0.69(0.17-2.72)$ & 0.429 \\
\hline
\end{tabular}

*Statistical significance and odds ratio for the dominant model (TA plus AA vs. TT). Statistically significant results $(p<0.05)$ indicated in bold.

in serum FGF2 levels was found between TT and TA genotypes (comparison was made for measurable levels of FGF2 $(n=23)$. We also determined whether the -553 T/A polymorphism of the FGF2 gene was associated with DFS and OS of BC patients. Survival analysis showed a significantly shorter DFS for carriers of the combined T/A-A/A genotypes when compared with carriers of the $T / T$ genotype $p=0.0119$ (Figure 1). No statistically significant association was found between polymorphic variants of the FGF2 gene and OS of BC patients, $p=0.2116$ (Figure 2).

\section{Discussion}

Fibroblast growth factor-2 expression is progressively elevated during initial phases of breast tumorigenesis, and its expression is higher in cancerous breasts in comparison with adjacent normal tissues or benign ones [11, 28]. In previous studies, we have also demonstrated that the growth factor FGF2 was higher in tumour and serum samples of $B C$ patients than in samples of benign breast disease patients [29]. These findings are in agreement with the previously reported studies, especially with 
Table IV. Average FGF2 level (median, quartiles) in serum and tumour tissue in subjects with breast cancer

\begin{tabular}{|lcc|}
\hline Genotype & \multicolumn{2}{c|}{ Average FGF2 level, median (quartiles) } \\
\cline { 2 - 3 } & Serum $[\mathrm{pg} / \mathrm{ml}]$ & Tumour tissue $[\mathrm{pg} / \mathrm{mg}$ protein] \\
\hline T/T & $166.07(52.14-351.79)$ & $1407.50(281.69-2262.46)$ \\
\hline T/A & $221.03(41.20-472.01)$ & $2135.14(723.03-3274.82)$ \\
& $p=0.920$ & $p=0.010$ \\
\hline Total of FGF2 & $167.32(41.75-354.75)$ & $1758.68(322.23-2323.00)$ \\
\hline
\end{tabular}

Statistically significant results $(p<0.05)$ indicated in bold.

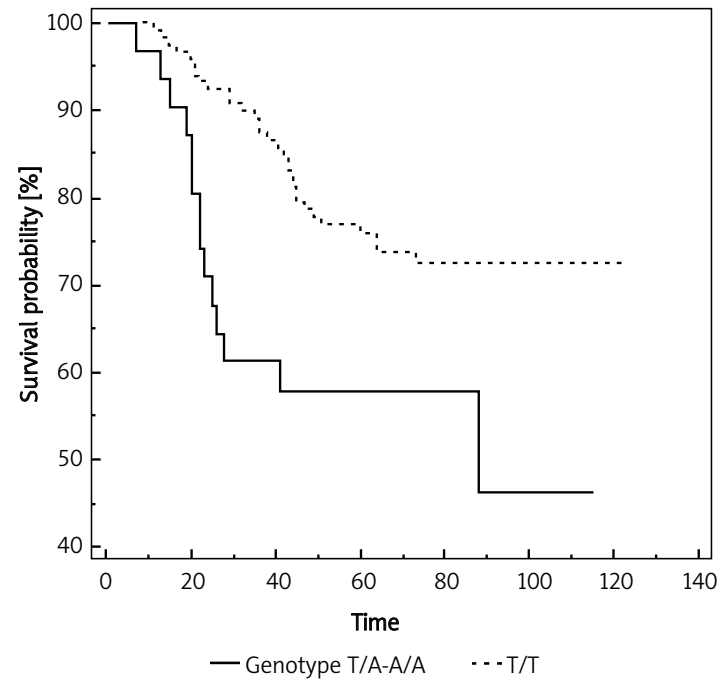

Figure 1. Kaplan-Meier disease-free survival (DFS) curves for breast cancer patients related to genotypes of -553 T/A FGF2 gene polymorphism; $p=0.0119 ; \mathrm{HR}: 0.4516(95 \% \mathrm{Cl}: 0.2119-0.9624)$

regard to FGF2 levels in tissues of cancerous breasts. It was demonstrated that not only BC tumour samples, but also high-risk breasts such as previous pre-cancerous lesions (atypical ductal hyperplasia or lobular carcinoma in situ), and breasts of patients with BC family history, produce an increased amount of FGF2 compared with benign ones [11, 30]. Moreover, in an animal model of spontaneous mammary tumour progression it was demonstrated that tumours developed in a much shorter time in FGF2 wild-type female mice compared to an FGF2 knockout cohort. Additionally, there was a significant difference in tumour growth rate between FGF2 knockout mice and the FGF2 heterozygous cohort, which suggests a gene dosing effect [31]. The delay in tumour onset supports a functional role for FGF2 in mammary tumour progression and the fact that these effects are dosedependent indicates the possibility that the genetic predisposition to excessive production of FGF2 may have an association with risk of BC occurrence. In this study on the Polish population we demonstrated a significant association between $-553 \mathrm{~T} / \mathrm{A}$ polymorphisms and the susceptibility to $B C$. The 553 TA genotype has a promotive effect for BC development. Additionally, in the $\mathrm{BC}$ group signifi-

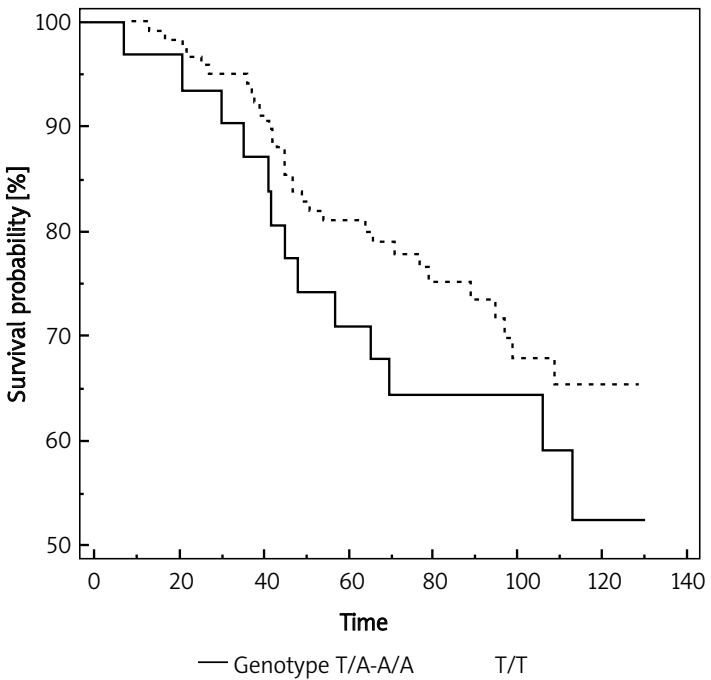

Figure 2. Kaplan-Meier overall survival (OS) curves for breast cancer patients related to genotypes of 553 T/A FGF2 gene polymorphism; $p=0.2611$; HR: 0.7104 (95\% Cl: 0.3681-1.3708)

cantly higher tumour levels of FGF2 were demonstrated in patients with the TA genotype of the 553 T/A polymorphism compared with patients with the TT wild-type genotype. We did not find a similar association in serum of these patients. These results suggest that $-553 \mathrm{~T} / \mathrm{A}$ polymorphism may be considered as a $\mathrm{BC}$ risk factor in the Polish population. To the best of our knowledge, this is the first study to examine -553 T/A FGF2 gene polymorphism in $B C$ risk and progression. However, several genome-wide association studies have shown that the SNP located in intron 2 of the fibroblast growth factor receptor 2 gene (FGFR2) is associated with increased BC risk [32, 33]. Taken together, these results suggest that variations in genes associated with FGF2-mediated signal transduction somehow modify the $\mathrm{BC}$ risk.

In order to explain the involvement of FGFs in $\mathrm{BC}$ progression, we examined the relationship between FGF2 levels and -553 T/A polymorphism and microvessel counts, ER, HER2, tumour grade and survival of $\mathrm{BC}$ patients. We did not observe any correlation of serum and tumour FGF2 levels with other clinical parameters except microvessel density (MVD) of BC tissue [29]. These results and many further investigations suggest that FGF2 is not an 
independent prognostic factor and the precise role of these signalling molecules in the pathogenesis and progression of breast tumour is still unclear $[12,13]$. Although FGF2 was the first pro-angiogenic molecule discovered, it has numerous activities in the growth and differentiation of non-vascular cell types and now it is known that activation of angiogenesis is not the main target for FGF2 during cancer development [31]. Several studies have demonstrated lack of a relationship between tumour microvessel counts and FGF2 levels, implying no direct involvement between FGF2 and angiogenesis $[30,34]$. A similar finding was reported when correlating vascular density with FGF2 mRNA [35]. Surprisingly, in our previous and one other study the FGF2 levels were inversely related to blood vessels $[29,36]$. Konstantinovsky et al. suggested a role for this growth factor in mediating tumour survival rather than angiogenesis [37]. This hypothesis is supported by data which demonstrate that a subset of $\mathrm{Bcl} 2$ family proteins are the targets of FGF2 signalling that promotes cell survival [38].

As we mentioned earlier, the prognostic value of FGF2 in primary $B C$ remains controversial; higher FGF2 expression correlated with improved overall survival $[17,39]$ but showed no relationship with survival in other reports $[34,40]$. We found no statistically significant association between polymorphic variants of the FGF2 gene and overall survival of $B C$ patients. However, we showed that the combined T/A-A/A genotypes were associated with significantly shorter DFS. Moreover, in this work was demonstrated an increased level of FGF2 in tumour of A allele carries, and this confirms that the A allele might predict worse DFS in BC patients.

These results, as well as previous studies, show that FGF2 is an important mediator in the initial steps of BC development but its impact on cancer progression and invasion is unclear. One of the possible explanations for this role is the relationship between FGF2 and HER-2. Several studies suggests that determination of HER2 overexpression in breast cancer patients, allows for a determination of a group of patients with a worse prognosis [41]. We showed that the A allele genotype was significantly associated with HER2 positive tumour ( $\mathrm{OR}=2.53,95 \% \mathrm{Cl}: 1.24-5.17)$. The association of the A allele driving the highest levels of FGF2 with HER2 positive tumours might be the result of FGF2's effect on HER2 gene regulation. It was found that FGF2 induced interaction between PEA3 and its response element, within the promoter region of HER2. HER2/neu promoter activity was decreased by deleting the PEA3 binding site, and was downregulated when the PEA3 binding site was mutated. The FGF2 upregulated the protein expression of PEA3 in human primary breast tumour cell cultures and this suggests that a high FGF2 level can contribute to an increase in HER-2 expression in BC cells, supporting a positive role for $F G F 2$ in $B C$ progression $[42,43]$. Although we did not observe higher FGF2 tumour and serum levels in patients with metastases in axillary lymph nodes, we demonstrated a correlation between -553 T/A genotype and this worse prognostic factor. Recent studies have also confirmed participation of FGF2 in the formation of lymph node metastases. FGF2 treatment increased AQP3 expression and induced cultured human BC cell migration in a dose-dependent manner [44]. Additionally, it was shown that FGF2 and lymphangiogenic factors (VEGF-C) collaboratively promote angiogenesis and lymphangiogenesis in the tumour microenvironment, leading to widespread pulmonary and lymph node metastases [45].

We did not find a significant correlation between A allele genotype and other clinical parameters: age at diagnosis, tumour grade, size, and hormonal receptor status (ER and PR). However, the frequency of the FGF2 A allele was marginally higher in ductal carcinomas than lobular carcinomas. It is an important finding because it is known that ductal carcinomas have poor prognosis. Lobular tumours are often slower growing than ductal tumours, and are more often oestrogen and progesterone receptor positive [46].

In conclusion, we hypothesized that genetic ability to produce high levels of endogenous FGF2 could promote $B C$, but these findings require replication in large samples and the role of these variants needs to be clarified by functional studies. The characterization of these and other polymorphisms in the FGF2 gene may help to understand better the aetiology and development of $\mathrm{BC}$, and to define risk groups to target prevention strategies.

\section{Acknowledgments}

This work was supported by grant no. 502-11568 from the Medical University of Lodz.

\section{Conflict of interest}

The authors declare no conflict of interest.

\section{References}

1. Cao Y, Cao R, Hedlund EM. Regulation of tumor angiogenesis and metastasis by FGF and PDGF signaling pathways. J Mol Med (Berl) 2008; 86: 785-9.

2. Kos M, Dabrowski A. Tumour's angiogenesis: the function of VEGF and bFGF in colorectal cancer. Ann Univ Mariae Curie Sklodowska Med 2002; 57: 556-61.

3. Mohammadi M, Olsen SK, Ibrahimi OA. Structural basis for fibroblast growth factor receptor activation. Cytokine Growth Factor Rev 2005; 16: 107-37.

4. Dirix LY, Vermeulen PB, Pawinski A, et al. Elevated levels of the angiogenic cytokines basic fibroblast growth factor 
and vascular endothelial growth factor in sera of cance patients. Br J Cancer 1997; 76: 238-43.

5. Nguyen M, Watanabe H, Budson AE, Richie JP, Hayes DF, Folkman J. Elevated levels of an angiogenic peptide, basic fibroblast growth factor, in the urine of patients with a wide spectrum of cancers. J Natl Cancer Inst 1994; 86: 356-61.

6. Bilgic I, Ozalp N, Tez M, Koc M. Serum bFGF concentrations in gastric cancerpatients. Bratisl Lek Listy 2008 ; 109: 8-9.

7. Bremnes RM, Camps C, Sirera R. Angiogenesis in nonsmall cell lung cancer: the prognostic impact of neoangiogenesis and the cytokines VEGF and bFGF in tumours and blood. Lung Cancer 2006; 51: 143-58.

8. Hase T, Kawashiri S, Tanaka A, et al. Correlation of basic fibroblast growth factor expression with the invasion and the prognosis of oral squamous cell carcinoma. J Oral Pathol Med 2006; 35: 136-9.

9. Horstmann M, Merseburger AS, von der Heyde E, et al. Correlation of bFGF expression in renal cell cancer with clinical and histopathological features by tissue microarray analysis and measurement of serum levels. J Cancer Res Clin Oncol 2006; 131: 715-22.

10. Faridi A, Rudlowski C, Biesterfeld S, Schuh S, Rath W, Schröder W. Long-term follow-up and prognostic significance of angiogenic basic fibroblast growth factor (bFGF) expression in patients with breast cancer. Pathol Res Pract 2006; 198: 1-5.

11. Sartippour MR, Zhang L, Lu M, Wang HJ, Brooks MN. Nipple fluid basic fibroblast growth factor in patients with breast cancer. Cancer Epidemiol Biomarkers Prev 2005; 14: 2995-8.

12. Granato AM, Frassineti GL, Giovannini N, et al. Do serum angiogenic growth factors provide additional information to that of conventional markers in monitoring the course of metastatic breast cancer? Tumour Biol 2006; 27 302-8.

13. Alba E, Llombart A, Ribelles N, et al. Serum endostatin and bFGF as predictive factors in advanced breast cancer patients treated with letrozole. Clin Transl Oncol 2006; 8: 193-9.

14. Pichon MF, Moulin G, Pallud C, Pecking A, Floiras JL. Serum bFGF (basic fibroblast growth factor) and CA 15.3 in the monitoring of breast cancer patients. Anticancer Res 2000; 20: 1189-94.

15. Hewala TI, Abd El-Moneim NA, Ebied SA, Sheta MI, Soliman K, Abu-Elenean A. Diagnostic and prognostic value of serum nitric oxide, tumor necrosis factor-alpha, basic fibroblast growth factor and copper as angiogenic markers in premenopausal breast cancer patients: a casecontrol study. Br J Biomed Sci 2010; 67: 167-76.

16. Sliutz G, Tempfer C, Obermair A, Dadak C, Kainz C. Serum evaluation of basic FGF in breast cancer patients. Anticancer Res 1995; 15: 2675-7.

17. Linderholm BK, Lindh B, Beckman L, et al. Prognostic correlation of basic fibroblast growth factor and vascular endothelial growth factor in 1307 primary breast cancers. Clin Breast Cancer 2003; 4: 340-7.

18. Van den Eynden GG, Van der Auwera I, Van Laere SJ, et al. Comparison of molecular determinants of angiogenesis and lymphangiogenesis in lymph node metastases and in primary tumours of patients with breast cancer. J Pathol 2007; 213: 56-64.

19. Sauer G, Schneiderhan-Marra N, Kazmaier C, et al. Prediction of nodal involvement in breast cancer based on multiparametric protein analyses from preoperative core needle biopsies of the primary lesion. Clin Cancer Res 2008; 14: 3345-53.
20. Chung HC, Rha SY, Ahn JB, et al. Menstrual state should be considered in determining sero-positivity of soluble angiogenic factors in breast cancer. Int J Mol Med 1998; 2: 465-70.

21. Przybylowska K, Kluczna A, Zadrozny M, et al. Polymorphisms of the promotor regions of matrix metalloproteinases genes MMP-1 and MMP-9 in breast cancer. Breast Cancer Res Treat 2006; 95: 65-72.

22. Blasiak J, Przybyłowska K, Czechowska A, et al. Analysis of the $\mathrm{G} / \mathrm{C}$ polymorphism in the 5 '-untranslated region of the RAD51 gene in breast cancer. Acta Biochim Pol 2003; 50: 249-53.

23. Mojgan $\mathrm{H}$, Massoud $\mathrm{H}$, Ahmad E. ERCC1 intron 1 was associated with breast cancer risk. Arch Med Sci 2012; 8: 655-8.

24. Hosseini M, Houshmand M, Ebrahimi A. MTHFR polymorphisms and breast cancer risk. Arch Med Sci 2011; 7: 134-7.

25. Beránek M, Tschöplová S, Kanková K, Kuhrová V, Vácha J. Genetic variation in the promoter region of the basic fibroblast growth factor gene. Hum Immunol 2008; 64: 374-7.

26. Petrovic MG, Krkovic M, Osredkar J, Hawlina M, Petrovic D. Polymorphisms in the promoter region of the basic fibroblast growth factor gene and proliferative diabetic retinopathy in Caucasians with type 2 diabetes. Clin Experiment Ophthalmol 2008; 36: 168-72.

27. Kariz S, Grabar D, Krkovic M, Osredkar J, Petrovic D. Polymorphisms in the promoter region of the basic fibroblast growth factor gene are not associated with myocardial infarction in a slovene population with type 2 diabetes. J Int Med Res 2009; 37: 1596-603.

28. Liu Y, Wang JL, Chang H, Barsky SH, Nguyen M. Breastcancer diagnosis with nipple fluid bFGF. Lancet 2000; 356: 567.

29. Rykala J, Przybylowska K, Majsterek I, et al. Angiogenesis markers quantification in breast cancer and their correlation with clinicopathological prognostic variables. Pathol Oncol Res 2011; 17: 809-17.

30. Polat A, Hazar B, Çolak T, Akça T, Karabacak T. Expression of basic fibroblastic growth factor (bFGF) in invasive ductal carcinoma of breast and its relation to angiogenesis and other prognostic parameters. Aegean Pathology Journal 2005; 2: 131-6.

31. Kao S, Mo J, Baird A, Eliceiri BP. Basic fibroblast growth factor in an animal model of spontaneous mammary tumor progression. Oncol Rep J 2012; 27: 1807-14.

32. Kawase T, Matsuo K, Suzuki T, et al. FGFR2 intronic polymorphisms interact with reproductive risk factors of breast cancer: results of a case control study in Japan. Int J Cancer 2009; 125: 1946-52.

33. Liang J, Chen P, Hu Z, et al. Genetic variants in fibroblast growth factor receptor 2 (FGFR2) contribute to susceptibility of breast cancer in Chinese women. Carcinogenesis 2008; 29: 2341-6.

34. Smith K, Fox SB, Whitehouse R, et al. Upregulation of basic fibroblast growth factor in breast carcinoma and its relationship to vascular density, oestrogen receptor, epidermal growth factor receptor and survival. Ann Oncol 1999; 10: 707-13.

35. Winstanley J, Annandappa S, Green B, Leinster S, Barraclough R, Rudland P. Acid and basic fibroblast growth factors and their relationship to vascular density. Eur J Cancer 1992; 30: S6.

36. Gravdal K, Halvorsen OJ, Haukaas SA, Akslen LA. Expression of bFGF/FGFR-1 and vascular proliferation related to clinicopathologic features and tumor progress 
in localized prostate cancer. Virchows Arch 2006; 448:

68-74.

37. Konstantinovsky S, Nielsen S, Vyberg M, et al. Angiogenic molecule expression is downregulated in effusions from breast cancer patients. Breast Cancer Res Treat 2005; 94: 71-80.

38. Kim HR, Heo YM, Jeong KI, et al. FGF-2 inhibits TNF-alpha mediated apoptosis through upregulation of Bcl2-A1 and Bcl-xL in ATDC5 cells. BMB Rep 2012; 45: 287-92.

39. Yiangou C, Gomm JJ, Coope RC, et al. Fibroblast growth factor 2 in breast cancer: occurrence and prognostic significance. Br J Cancer 1997; 75: 28-33.

40. Eppenberger U, Kueng W, Schlaeppi JM, et al. Markers of tumor angiogenesis and proteolysis independently define high- and low-risk subsets of node-negative breast cancer patients. J Clin Oncol 1998; 16: 3129-36.

41. Badowska-Kozakiewicz AM, Sobol M, Patera J, Kozłowski W. Immunohistochemical evaluation of human epidermal growth factor receptor 2 and estrogen and progesterone receptors in invasive breast cancer in women. Arch Med Sci 2013; 9: 466-71.

42. Myers E, Hill AD, Kelly G, et al. A positive role for PEA3 in HER2-mediated breast tumour progression. Br J Cancer 2006; 95: 1404-9.

43. Matsui K, Sugimori K, Motomura H, Ejiri N, Tsukada K, Kitajima I. PEA3 cooperates with c-Jun in regulation of HER2/neu transcription. Oncol Rep 2006; 16: 153-8.

44. Cao XC, Zhang WR, Cao WF, et al. Aquaporin3 is required for FGF-2-induced migration of human breast cancers. PLoS One 2013; 8: e56735.

45. Cao R, Ji H, Feng N, et al. Collaborative interplay between FGF-2 and VEGF-C promotes lymphangiogenesis and metastasis. Proc Natl Acad Sci U S A 2012; 109: 15894-9.

46. Coradini D, Pellizzaro C, Veneroni S, Ventura L, Daidone MG. Infiltrating ductal and lobular breast carcinomas are characterised by different interrelationships among markers related to angiogenesis and hormone dependence. $\mathrm{Br}$ J Cancer 2002; 87: 1105-11. 